\title{
Bailes de negros
}

\author{
Gonzalo Aguirre Beltrán
}

En el campo de la etnohistoria en México, es sin duda la figura de Gonzalo Aguirre Beltrán una de las que se destaca como pionero en esta disciplina. Desde 1942 inicia sus estudios en el Archivo General de la Nación sobre los pobladores de origen africano que se encuentran en México, y constata la información de los archivos con la realidad de los pueblos de origen africano que se encuentran en las costas de México. Su labor va más allá del trabajo exclusivo del archivo, como él mismo señala: "El análisis histórico complementado por el trabajo de campo antropológico da su figura al estudio etnohistórico, método de investigación que ilumina el examen de los problemas del pasado y presente."

\footnotetext{
${ }^{1}$ Aguirre Beltrán, Gonzalo, Obra antropológica, vol. XVI, El negro esclavo en Nueva España, la formación colonial, la medicina popular y otros ensayos, México, Universidad Veracruzana, Instituto Nacional Indigenista, Gobierno del estado de Veracruz, Centro de Investigaciones y Estudios Superiores en Antropología Social y Fondo de Cultura Económica, 1994.
}

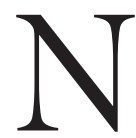

O SIEMPRE es posible demostrar con suficiente evidencia el origen de rasgos y complejos culturales que hoy son parte consustancial de los patrones de comportamiento habituales en los mexicanos o en una porción de ellos. Es sabido que en nuestro país concurrieron, desde los años del descubrimiento y conquista de la Tierra Firme, dos grupos de población bien identificados por participar en sistemas de vida que diferían considerablemente entre sí: los españoles y los indios. Con cierta razón, ambos grupos fueron objetivados en categorías sociales únicas.

Con la designación de españoles se comprendían, por supuesto, a los que en la actualidad componen las variadas nacionalidades del Estado español: castellanos, vascos, catalanes, gallegos, etcétera; pero también eran portugueses de la propia Península Ibérica, nórdicos de los Países Bajos, alemanes del Báltico, italianos y griegos del Mediterráneo. No obstante que hablaban lenguas que no permitían el entendimiento común y que en su modo de ser expresaban las peculiaridades que les daba una identidad nacional, todos quedaban incluidos en el ámbito de la cultura occidental, compartían un estilo de vida general y representaban una etapa de civilización urbana muy semejante.

Las divergencias en la categoría social india eran claramente mayores. En ella se incluían, tanto las bandas recolectoras cazadoras de los semidesiertos del norte del país, cuanto los pueblos agrícolas del centro y sur, entre los cuales algunos, como los nahuas del valle de México, 
los mayas del procurrente yucateco, los zapotecas y mixtecas de Oaxaca, los totonacas de Veracruz, habían alcanzado elevados niveles de eficiencia en muy diversos aspectos de su civilización. La dispersión idiomática, que había producido más de un centenar de lenguas y un crecido guarismo de dialectos, y las formas de obtener las subsistencias ya mencionadas, separaban a los componentes de esta categoría social; pero todos eran americanos, es decir, gente sentida como radicalmente distinta por sus conquistadores, especialmente en lo que concierne a civilidad y policía.

A pesar de la clara participación que desde un principio puso aparte a las dos categorías que nos ocupan, los etnólogos que en el presente estudian a las comunidades que descienden directamente de los grupos étnicos americanos, encuentran a menudo difícil la determinación de los rasgos nativos y extranjeros. En muchas de esas comunidades, si hemos de creer a los antropólogos difusionistas, con excepción del habla y unas pocas cosas más, todos los rasgos culturales son de procedencia occidental. Según ello, la contribución que los indios actuales pueden dar a la formación de la cultura nacional es despreciable. Otros especialistas en ciencias sociales y en humanidades, que se ocupan de investigar a grupos de población nacional, tienen dificultades parecidas cuando siguen el rastro a un elemento cultural cualquiera para descubrir su forma prístina. Desde luego, hay rasgos cuya calificación como americanos u occidentales es obvia: objetos, técnicas, alimentos, vestidos, viviendas. Pero en otros apartados de la cultura, como los ubicados en los dominios del arte, la religión y la medicina, las cosas son diametralmente opuestas. No hay seguridad alguna para definir la procedencia cultural. Por ejemplo, la creencia en el susto, tan importante en la medicina popular, bien puede proceder del pensamiento mágico cristiano sobre el espíritu o del concepto nahua del tonalli.

La dicotomía arriba establecida, con todo y las dificultades graves que a veces confronta, sólo exige la elección entre los componentes de dos grandes sistemas culturales, el occidental y el americano. Un objeto o una idea sólo pueden ser españoles o indios, con ello la pesquisa queda restringida dentro de una jurisdicción relativamente reducida; la Península Ibérica, en un caso, la superficie

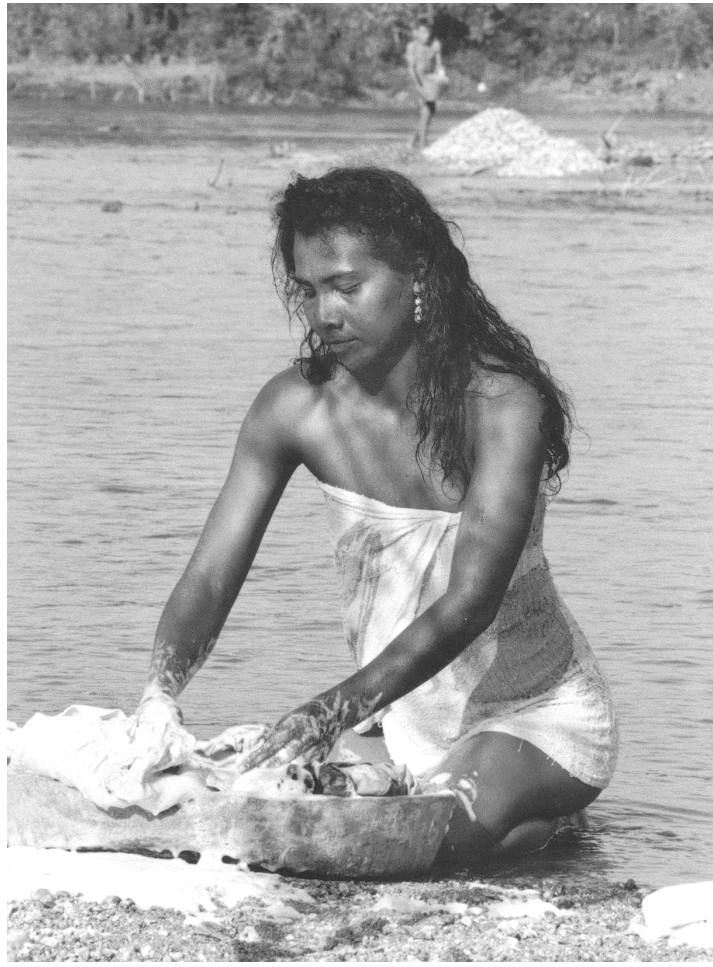

Collantes, afromexteca de la Costa, Vittorio D’Onofri, 1995

patria, en el otro. A decir verdad, esta limitación no tiene en cuenta la participación en la población colonial de gente distinta a la mencionada. Se sabe que México recibió inmigración negra que vino de África y el Asia que fue introducida por el puerto de Acapulco; pero jamás se da beligerancia a esta gente, es juicio común que pasó sin dejar huella.

El número de asiáticos forzosamente inmigrados a Nueva España parece haber sido corto y su influencia reducida al hinterland del puerto de entrada; pero en lo que concierne al negro las cosas son indudablemente distintas. Los estudios llevados a cabo sobre el número de los que migraron al país, la proporción en cuanto a edad y sexo de los esclavos, la procedencia tribal de los mismos, su distribución geográfica en la extensión del territorio colonial. Los años en que se introdujo, el trato que se les dio y otros pormenores más, han permitido un conocimiento suficiente de este grupo racial para afirmar, sin temor a dudas, su importancia. 
Aunque estos estudios representan tan sólo un punto de partida para investigaciones posteriores, que les afinen y den profundidad que requieren, el mundo académico de México se encuentra poco interesado en esta línea de pesquisa. La importancia que entre nosotros tiene el indio y lo indio nos lleva a ignorar cualquier otra contribución a la cultura nacional, a más de la occidental, y esto reza particularmente con el negro. Durante el siglo pasado y principios del presente nuestros pensadores llegaron a travesear con ideas racistas en las que excluyen al indio pero no al negro. Se rehusa la contribución cultural africana o simplemente no se reconoce.

Lo que antecede coloca al afromexicanista en una posición muy particular. Si trata de calificar como africano un rasgo o un complejo cultural, presente en nuestro estilo de vida, se encuentra obligado a ofrecer una evidencia incontrovertible que muy a menudo es imposible encontrar; los paralelismos entre costumbres africanas y americanas le inducen a error, y el proceso de aculturación que operó y sigue operando incansable borra los perfiles acusados de los elementos originales hasta volverlos irreconocibles. Todo lo anterior viene a cuento porque el presente trabajo pretende señalar una influencia africana en los bailes populares de México con base en la documentación colonial.

En otro lugar hemos narrado con toda minuciosidad los lugares tan diversos de donde fueron arrancados los negros por los tratantes de esclavos (Aguirre Beltrán, 1946); así pues, baste decir aquí que la mayoría procedió, según las épocas, de las áreas culturales de la Costa de Guinea y del Congo, según lo formula Herskovits (1924: 56-63). La limitación geográfica cultural del territorio africano en que tuvieron su origen la mayor suma de negros significa sólo similitud de formas de vida, pero en modo alguno de comunidades de habla. Los idiomas bantús y los que permitían la comunicación entre los verdaderos negros eran muchos; tantos que el castellano se convirtió en la lengua franca de la esclavonía.

La diversidad de origen junto con las condiciones de la esclavitud, esencialmente destructoras de la cultura, propiciaron la integración de los africanos en la cultura de las minas, los obrajes, las plantaciones y el servicio doméstico. La ecología de las urbes y la de las explotaciones capitalistas ubicadas en el Altiplano eran distintas a las africanas, sólo en las costas tropicales del Golfo y el Pacífico los negros encontraban algo semejante a su patria; pero ni aún en este último caso pudo grupo tribal alguno recrear el estilo de vida que había dejado atrás. La destrucción de la cultura original y la adopción de la cultura enajenada del conquistador fue el destino general del negro.

Por supuesto, el negro resistió hasta donde le alcanzaron las fuerzas la demolición de todo aquello que daba significado a su vida y en no pocas ocasiones se sublevó contra el amo español o simplemente huyó a los refugios que le depararon las selvas, los desiertos o las montañas. $\mathrm{Ni}$ aun en este caso llegó a reconstruir su sistema cultural. Los cimarrones vivían en palenques sujetos a un orden social cuya cohesión les permitía rechazar con éxito los ataques de los colonos esclavistas; pero este orden era una reinterpretación de formas occidentales o americanas. La economía se basaba en la producción del maíz conforme a la técnica indígena, y la organización política se configuraba de acuerdo con las normas que los españoles dieron a la república de indios.

No obstante todo lo dicho, tanto los negros horros cuanto los esclavos, supieron conservar ciertas expresiones, que actuaron a manera de cemento para mantenerlos unidos: las expresiones estéticas. Los domingos y fiestas de guardar eran para los negros, abrumados por el diario trabajo, el tiempo libre en que la sociedad esclavócrata se veía compelida a permitirles tañer, cantar, bailar y embriagarse. Al través de estas expresiones la música, el canto y la danza africanas tendían a perdurar. La excitación dionisiaca que caracteriza muchos de los bailes africanos causó profundo recelo y gran temor en los amos (AGN, Reales Cédulas en Duplicados, 3. 28). A veces quisieron prohibir las reuniones tumultuosas; pero, ante la imposibilidad de lograrlo, se conformaron con regularlas (AGN, Reales Cédulas en Duplicados, 103. 93).

El escándalo que provocaron los bailes de negros no se limitó a los amos. Se extendió a los gobernantes encargados del poder civil y a los eclesiásticos que dominaban las conciencias, al comprobar la intromisión de los esclavos en los bailes, y celebraciones de los indios. Los comisarios y familiares del Santo Oficio de la Inquisición, en las denuncias que elevaron a sus superiores dejaron 
constancia de esta penetración y de la de opuesto sentido. Los negros, informan, bailan con los indios el nonteleche, representación de un sacrificio humano, los patoles en las ceremonias de imposición del nombre y los areitos destinados a los dioses indios (AGN, Inquisición, 303. 357; 304. 190; 303. 39).

La mutua influencia de una cultura sobre otra tuvo lugar especialmente entre la negra y la blanca. El contacto más frecuente del negro fue sin duda el que tuvo con el amo blanco. Por parte de éste hubo un esfuerzo decidido por cristianizar y ladinizar al bozal con el fin de integrarlo a la economía colonial como proletario. El esclavo, a su vez, hizo ostensibles esfuerzos por vestir sus bailes con la indumentaria occidental y la representación del culto y los santos católicos. Hace trescientos años, concursos de negros ejecutaban por las calles de las ciudades mexicanas, bailes en cortejo que bien pueden ser el antecedente de los candombés sudamericanos.

En efecto, de mediados del siglo XVII, cuando alcanzó su ápex la inmigración negra a Nueva España, data una denuncia al Santo Oficio en la que se afirma: "fueron hombro turibulando las imágenes en esta ciudad; abuso introducido de pocos años a esta parte en la ciudad de los Ángeles" (AGN, Inquisición, 686. 7). El denunciante temía la difusión de la práctica a los indios que eran más que los negros en la jurisdicción de Puebla. En Guadalajara también se ejecutaban estos bailes en que negros y mulatos se agrupaban en naciones, conforme al testimonio de un clérigo. "Entre los negros y mulatos de esta tierra se han erigido comunidades, aunque para los Señores de la ciudad es una lícita diversión, para otros y para mí no lo es" (AGN, Inquisición, 897. 374).

Los negros, ciertamente, se habían vuelto cristianos, pero, a su vez habían infiltrado en las ceremonias religiosas un carácter festivo y secular que asustó a los sacerdotes celosos de mantener prístina la doctrina y la liturgia tradicionales (AGN, Inquisición, 612. 6; 677. 39). El 2 de diciembre de 1643 el Santo Oficio prohibió los nacimientos, conventículos, juntas y oratorios "concurso de gente, bailes y chocolates” (AGN, Inquisición, 728. 261). Los españoles, negros y mulatos de la ciudad de Puebla en contravención al edicto siguieron bailando los oratorios.
En 1689 fue recordada la interdicción, sin éxito, en Oaxaca; en 1704, con resultados semejantes en Guatemala. El año de 1789, se formó un expediente en Oaxaca contra negros, mulatos y españoles "sobre las deshonestidades y abusos introducidos con motivo de los coloquios que hacen en las navidades" (AGN, Inquisición, 1202. 18).

Un siglo antes, el comisario del Santo Oficio en Cuernavaca había excomulgado "a todos cuantos habían asistido en San Antonio Zacatepec a la fiesta y bailes que la gente libre y esclava del Real del dicho Ingenio habían hecho a la Virgen y Mártir Santa Catalina” (AGN, Inquisición. 661. 1). Pena tan severa para los devotos católicos del mundo colonial era de suponerse tuviera un efecto determinante en la yugulación de los bailes de negros, mas todo indica que no fue así. En realidad durante el siglo XVII hubo un estira y afloja entre prohibición y licencia, entre cantos y bailes permitidos y condenados, entre operaciones española deliberada y negra espontánea, es decir, se produjo una interacción que vino finalmente a originar el baile y el canto mestizos, pero mestizos principalmente de español y negro.

Esta emergencia tiene lugar a fines del siglo XVIII, precisamente cuando insurgen en los pensadores de la época ideas de patria y nacionalidad. Los bailes, siempre acompañados por el canto, se difunden por toda la colonia pero en lo particular por los centros de desarrollo capitalista: la ciudad de México, Puebla, Guanajuato, Morelia, Guadalajara, Pachuca y el puerto de Veracruz. Los giros de la danza son generalmente calificados de licenciosos, y la letra de las canciones de irreverentes, como en efecto lo eran. Parece como si el racionalismo de la Ilustración hubiese usado el canal de la copla para dar rienda suelta a su anticlericalismo.

En el archivo de la Inquisición numerosos expedientes, de fines del XVIII, informan con amplitud respecto a la aparición sucesiva e inacabable de bailes y cantares. Algunos de ellos los transcribiremos in extenso. En 1767, el comisario del Santo Oficio en Veracruz, decía:

Con fecha de 23 de septiembre me ordena Vuestra Señoría relacione sobre el baile que llaman el chuchumbé; las circunstancias con que se bailan y informado por dos sujetos, me dicen que las coplas que remití se cantan mientras los otros bailan, o ya sea entre hombres y mujeres, o sea bailando 


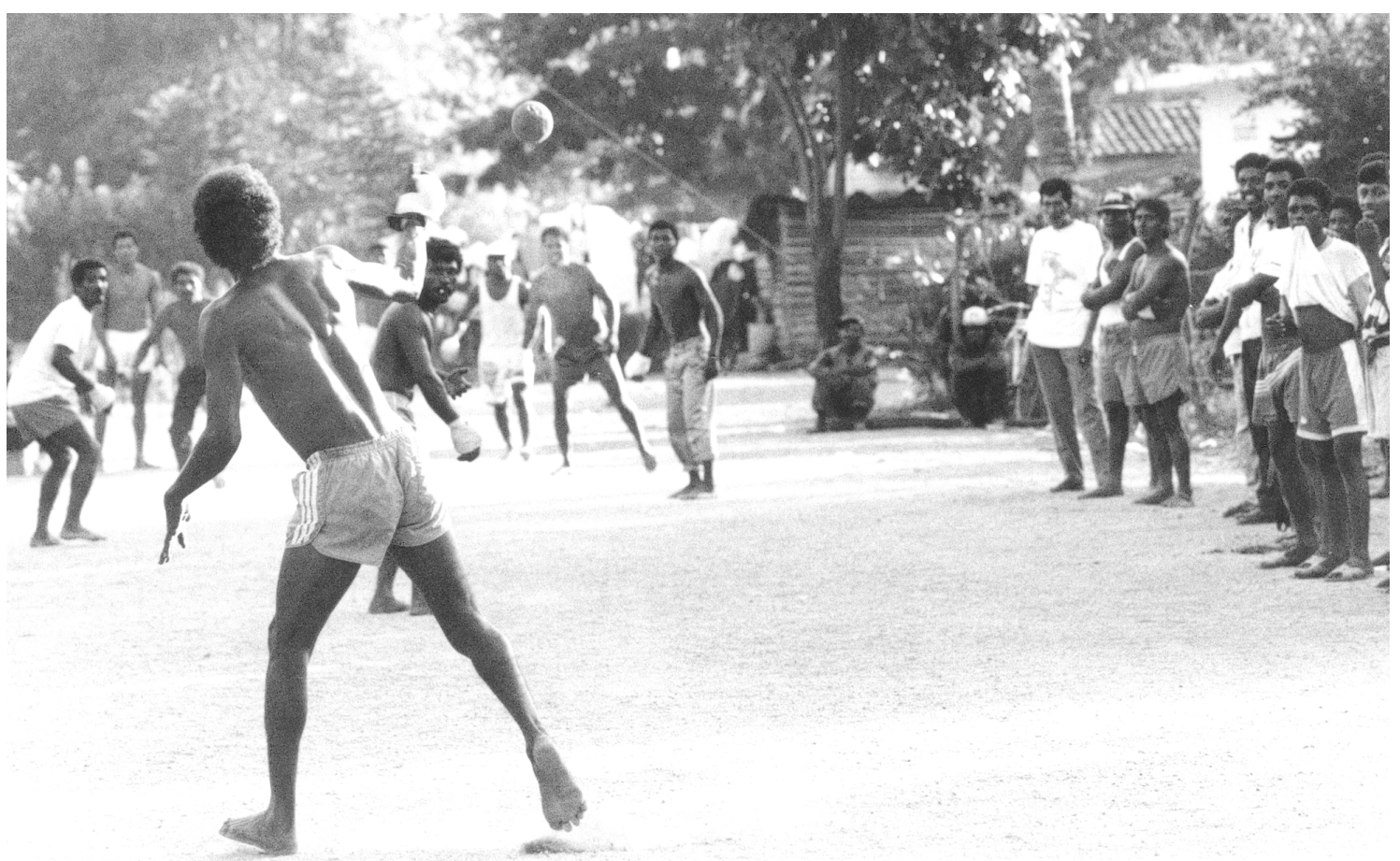

Santa María Jicaltepec, afromixteca de la Costa, Vittorio D’Onofri, 1995

varias mujeres con cuatro hombres, y que el baile es con ademanes, meneos, sarandeos, contrarios todos a la honestidad y mal ejemplo, de los que lo ven como asistentes, por mezclarse manoseos, de tramo en tramo abrazos y dar barriga con barriga, bien que también me informan que éste se baila en casas ordinarias de mulatos y gente de color quebrado, no en gente seria, ni entre hombres circunspectos y sî soldados, marineros y brosa (AGN, Inquisición, 1057. 20).

En la ciudad de México tuvo gran aceptación, por 1771, un son llamado saranguandinga, que se bailaba y cantaba en las tepacherías de la capital, desde el puente de Santo Domingo hasta el de Amaya y la Pila Seca. Se decía que los cantares eran muy deshonestos y que se bailaba con tanta desenvoltura que "sirve de grande provocación para excitar la lujuria” (AGN, Inquisición, 1168. 19). En 1778 causaba furor en Guanajuato el Son de los panaderos, en que:

Van saliendo cuantos concurren el fandango, pero acompañados siempre hombre y mujer y quedándose en el puesto que les toca, bailan y cantan, formando al fin porterías de monjas, baratillos, fandangos y todo comercio y comunicación de hombres y mujeres hasta que no queda grande ni chico, y cuanta mezcla hay, sea lo que fuere, que no salga a hacer algo. Se dio principio por un demonio, que ya se fue, en forma de mujer, que vino de Valladolid y dejó esta mala semilla sembrada (AGN, Inquisición, 1178. 2).

Por el mismo año de 1778 , en Veracruz se bailaba el son llamado maturranga y otros más, según una delación que en parte dice:

...por divertirme el día veinte de enero de este año entré a un baile que se tenía en el callejón que llaman de la Campana, en una casa cuyo dueño no conoce, y que está poco más adelante de la entrada del dicho callejón, y en una pareja de hombre y mujer, que con otra igual había salido a bailar el son que llaman el pan de manteca observé entre ellos movimientos muy lascivos, torpes, provocativos [...] pidió tocaran la cosecha que el dicho Tomás salió a bailar con una mujer y empezaron a bailar con gran deshonestidad [...] pero que hay otro baile llamado sacamandú el cual siempre que lo ha visto bailar le ha parecido muy deshonesto, que dicen que lo trajo un negro de la Habana, que estuvo forzado en el castillo de San Juan de Ulúa (AGN, Inquisición, 1178. 1) 
Por 1784, los mulatos de las minas de Pachuca cantaban y bailaban el pan de jarabe y sones como el viaje del arriero y el pan girado (AGN, Inquisición, 1297. 2; 1362. 10). Las coplas que acompañan a todos estos sones fueron recogidas por los comisarios del Santo Oficio. Las que acompañan al chuchumbé describen la corrupción de clérigos, mílites y funcionarios de época y hacen mofa de ello. En cierta forma la crítica que hacen es muy semejante a la de los cantadores de nuestros días y aun los bailes han persistido en algunos lugares sin gran modificación. El vívido relato que el comisario del Santo Oficio en Veracruz hizo del son llamado el torito bien podría retratar el que se baila hoy día: dice:

Tenemos la desgracia de oír entre la gente plebeya de esta ciudad y los pueblos comarcanos otro son llamado el torito, deducido del antiquísimo tango, que no he visto bailar, pero repetidas veces he oído detestar entre las personas que presenciándolo no han podido sacrificar en obsequio de la diversión los remordimientos de su conciencia, ni los sentimientos de la religión. Báilase el detestable torito entre un hombre y una mujer, ésta regularmente es la que sigue el ademán de torear, como el hombre el de embestir, la mujer provoca y el hombre se desordena: el hombre todo se vuelve embestir a la toreadora y la mujer toda se desconcierta o se vuelve banderillas para irritar al toro; en los movimientos de torear y en los de embestir uno y otra mutuamente se combaten, y ambos torean y embisten a los espectadores, que siendo por lo común personas tan libertinas y disolutas como los espectáculos, fomentan con gritos y dichos la desenvoltura y la liviandad de los perniciosos bailadores. Este baile, Ilustrísimo Señor, no es de aquellos que se ven de tarde en tarde, es bastante frecuente y creo que no hay concurrencia de arpa y guitarra, especialmente en las casas de campo, en las pequeñas de la ciudad y los pueblos de Medellin, Jamapa y Antigua Veracruz en que no se vea bailar, unas veces con más, otras con menos desenvoltura; pero casi siempre con demasiada disolución (AGN, Inquisición, 1410. 1).

Los documentos, citados en su parte significativa, proceden todos del Archivo General de la Nación, donde están a la disposición del público lector; pero no son los únicos. En los libros de cabildos en los archivos de las catedrales de las diócesis principales hay materiales sobre bailes de negros que esperan clasificación e interpretación. El presente trabajo intenta mostrar los antecedentes africanos de la música, el baile y el canto populares en

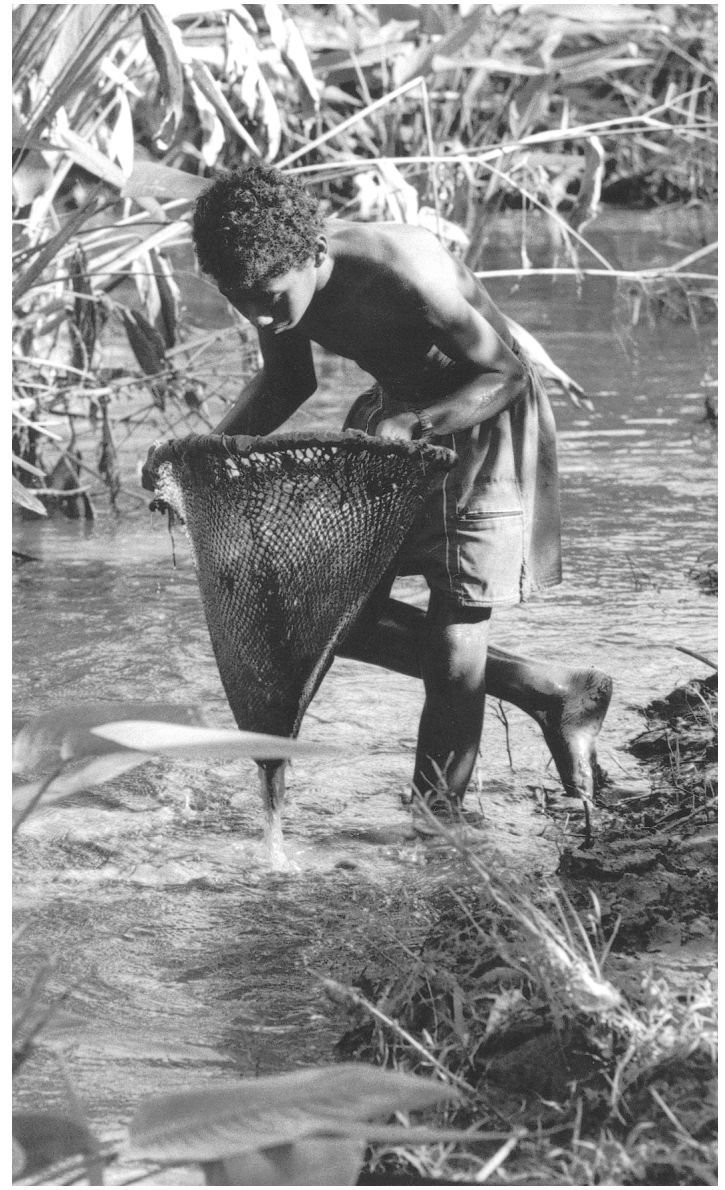

Corralero, afromixteca de la Costa, Vittorio D’Onofri, 1995

México, pero no lo considera una investigación exhaustiva sino, todo lo contrario, el punto de partida para posteriores estudios en profundidad.

Por otra parte, sólo toma en cuenta la fase histórica de la pesquisa. Investigaciones sobre la música, el baile y el canto actuales en la costa del Golfo han sido emprendidas por el Instituto de Antropología de la Universidad Veracruzana. La complementariedad de ambos enfoques, el histórico y el actual, es la sustancia de los estudios etnohistóricos. La productividad de la aproximación dual está fuera de toda duda; al realizarse con rigor científico demostrará, con claridad y mayores razones que las que aquí se ofrecen, un aspecto cardinal de la contribución negra al acervo cultural mexicano. 